Virginia Commonwealth University

vCU Scholars Compass

Psychology Publications

Dept. of Psychology

2014

\title{
Targeting tobacco in a community-based addiction recovery cohort: Results from a computerized, brief, randomized intervention trial
}

\author{
Alison Breland \\ Virginia Commonwealth University, abbrelan@vcu.edu \\ Lauren Almond \\ Virginia Commonwealth University, almondlm@vcu.edu \\ Jennifer Kienzle \\ Virginia Commonwealth University, jnkienzle@gmail.com \\ See next page for additional authors
}

Follow this and additional works at: http://scholarscompass.vcu.edu/psyc_pubs

Part of the Psychology Commons, and the Substance Abuse and Addiction Commons

(C) 2014 Elsevier Inc. NOTICE: this is the author's version of a work that was accepted for publication in Contemporary Clinical Trials. Changes resulting from the publishing process, such as peer review, editing, corrections, structural formatting, and other quality control mechanisms may not be reflected in this document. Changes may have been made to this work since it was submitted for publication. A definitive version was subsequently published in Contemporary Clinical Trials, [vol 38, issue 1, May 2014] doi:10.1016/j.cct.2014.03.008.

\section{Downloaded from}

http://scholarscompass.vcu.edu/psyc_pubs/8

This Article is brought to you for free and open access by the Dept. of Psychology at VCU Scholars Compass. It has been accepted for inclusion in Psychology Publications by an authorized administrator of VCU Scholars Compass. For more information, please contact libcompass@vcu.edu. 
Authors

Alison Breland, Lauren Almond, Jennifer Kienzle, Steven J. Ondersma, Alton Hart, Michael Weaver, Pamela Dillon, and Dace Svikis 
Targeting Tobacco in a Community-Based Addiction Recovery Cohort

Targeting Tobacco in a Community-Based Addiction Recovery Cohort:

Results from a Computerized, Brief, Randomized Intervention Trial

Alison B. Breland, $\mathrm{PhD}^{1}$; Lauren Almond, BS ${ }^{1}$; Jennifer Kienzle, PhD; Steven J. Ondersma, $\mathrm{PhD}^{2}$; Alton Hart, Jr., MD, MPH${ }^{3}$; Michael Weaver, $\mathrm{MD}^{1}$, Pamela Dillon, $\mathrm{PhD}^{1}$, Dace Svikis, $\mathrm{PhD}^{1}$

${ }^{1}$ Virginia Commonwealth University, ${ }^{2}$ Wayne State University, ${ }^{3}$ Virginia Department of Health

Correspondence should be addressed to:

Alison B. Breland, PhD

Institute for Drug and Alcohol Studies

Virginia Commonwealth University

PO Box 980310

Richmond, VA 23298-0310

abbrelan@vcu.edu 
Names and Addresses of Authors:

Alison B. Breland, PhD

Senior Research Associate

Institute for Drug and Alcohol Studies

Virginia Commonwealth University

PO Box 980310

Richmond, VA 23298

Phone: 804-628-2300

E-mail: abbrelan@vcu.edu

Lauren Almond, BS

Research Assistant

Institute for Drug and Alcohol Studies

Virginia Commonwealth University

PO Box 980310

Richmond, VA 23298

Phone: 804-628-2300

E-mail: almondlm@vcu.edu

Jennifer Kienzle, $\mathrm{PhD}$

PO Box 980343

Richmond, VA 23219

E-mail: jnkienzle@gmail.com

Steven J. Ondersma, PhD

Associate Professor

Merrill Palmer Skillman Institute

Wayne State University

71 East Ferry

Detroit, MI 48202

Phone: (313) 664-2504

E-mail: $\underline{\text { s.ondersma@wayne.edu }}$

Alton Hart, Jr., MD, MPH

Public Health Director

Virginia Department of Health

Crater Health District

301 Halifax Street

Petersburg, VA 23803

Phone: (804) 862-8988

E-mail: alton.hart@vdh.virginia.gov 
Michael Weaver, MD

University of Texas Health Sciences Center at Houston

Department of Psychiatry and Behavioral Sciences

1941 East Road, Suite 1222

Houston, TX 77054

Phone: (713) 486-2558

E-mail: Michael.F.Weaver@uth.tmc.edu

Pamela Dillon, PharmD

Research Liaison

Center for Clinical and Translational Research

Virginia Commonwealth University

PO Box 980261

1200 E. Clay Street, Suite 2000

Richmond, VA 23298

Phone: (804) 827-1519

E-mail: pmdillon@vcu.edu

Dace Svikis, $\mathrm{PhD}$

Professor

Department of Psychology

Virginia Commonwealth University

PO Box 980343

Richmond, VA 23219

Phone: (804) 827-1184

E-mail: dssvikis@ vcu.edu 


\begin{abstract}
Introduction. Nearly $80 \%$ of substance dependent individuals also use tobacco, and smoking cessation efforts during treatment for other substance use is associated with similar or even improved outcomes. However, smoking cessation is not routinely addressed during treatment for substance use disorders. The present study tested a computerized brief motivational intervention (C-BMI) for smoking cessation in an understudied population: a cohort recruited from a recovery community organization (RCO) center. Methods. Following baseline assessment, participants were randomly assigned to either a 30-minute C-BMI plus access to free nicotine replacement therapy (NRT), or an information-only control group plus NRT access. Results. Reductions in CO were observed for both groups. Quit rates in the C-BMI group (5\%$7 \%$, vs. $0 \%$ for the control group) approximated those observed elsewhere for physician advice and minimal counseling. Participants in the C-BMI group were also more likely to express a desire to quit. Conclusions. Computer-delivered smoking cessation interventions within RCOs appear feasible. These organizations treat a wide variety of individuals, and C-BMIs for smoking in this context have the potential to reduce smoking-related morbidity and mortality.
\end{abstract}

Keywords: smoking cessation, substance abuse recovery, brief interventions 


\section{INTRODUCTION}

Each year, over 400,000 people in the US die from cigarette smoking-related illnesses, making cigarette smoking the single most preventable cause of death in the US (CDC, 2012; CDC, 2008; Mokdad, Marks, Stroup \& Gerberding, 2004). Tobacco use is particularly common among persons with other substance use disorders (SUDs); in those with alcohol dependence, smoking rates may be as high as $80 \%$ (Hughes, 1995; Kalman, Morrisette \& George, 2005). The high rates of smoking among those with SUDs and mental health problems has been referred to as a "neglected epidemic" (Schroeder \& Morris, 2010).

Smoking cessation is rarely addressed in substance abuse treatment programs. (e.g., Friedmann, Jiang \& Richter, 2008; Hunt, Cupertino, Garrett, Friedman, \& Richter, 2012). Outside of formal treatment, access to smoking cessation programs may be even more limited, and many individuals accessing non-formal treatment are smokers. For example, in one study of individuals attending Alcoholics Anonymous meetings, 57\% smoked cigarettes (Reich, Dietrich, Finlayson, Fischer \& Martin, 2008). Although smoking cessation treatment is limited, many individuals with SUDs are interested in quitting; in one study, $49 \%$ of participants with SUDs reported a "strong desire to quit" (Orleans \& Hutchinson, 1993). In a similar study with persons in recovery, $70 \%$ were either contemplating or preparing to quit (Nahvi, Richter, Li Modali \& Arnsten, 2006).

Recovery community organizations (RCOs) offer peer-based recovery support services as well as education and advocacy; there are nearly 200 RCOs in the US (www.facesandvoicesofrecovery.org). The services offered are often separate from formal inpatient or outpatient treatment, and we are not aware of any studies have evaluating smoking cessation interventions in the context of recovery community organizations. This supportive 
context, outside of the traditional treatment system, may provide an ideal opportunity to address smoking cessation.

Brief interventions such as physician advice to quit smoking have been shown to increase quit rates (Fiore, 2008; Stead, Bergson, \& Lancaster, 2008). The most commonly used approach in studies of brief intervention for smoking cessation is the evidence-based 5As brief intervention model (Ask, Advise, Assess, Assist, and Arrange) for smoking cessation, as outlined by Fiore et al. (2008). Smoking cessation interventions using Motivational Interviewing approaches can also increase quit rates (Heckman, Egleston \& Hofmann, 2010; Hettema \& Hendricks, 2010; Lai, Cahill, Qin \& Tang, 2010). Because they can be delivered in a single, relatively brief session, brief interventions are ideally suited for use in many settings. Computerdelivered brief smoking interventions may prove even easier to disseminate, and have been supported in a number of trials, and in a recent review and meta-analysis (Chen et al., 2012; Shahab \& McEwen, 2009). However, none of these studies have focused on technologydelivered brief interventions for persons receiving services for other SUDs.

The objectives of this study were to: 1) examine interest in quitting smoking among individuals with SUDs attending a local recovery center, and 2) conduct a pilot randomized controlled trial to test the effectiveness of a computerized brief motivational intervention for smoking cessation (C-BMI) vs. an information-only control condition in this population. 


\section{METHODS}

\section{Participants}

Participants were recruited from an urban RCO center in Virginia. This RCO provides services such as 12-step meetings, referral to resources, and weekly events for individuals in recovery. Most clients are referred by treatment agencies for support while waiting for formal treatment, for continuing care after formal treatment has ended, or they are addressing their recovery on their own. This RCO serves approximately 500 clients annually. To participate, participants had to be 18 years of age or older, in recovery from addiction to alcohol and/or drugs (self-defined), state that they had smoked at least 100 cigarettes (lifetime), report smoking at least one cigarette per day for the past seven days or at least 10 cigarettes total during the past week, have an expired air carbon monoxide (CO) level of $\geq 6 \mathrm{ppm}$ (to verify current smoking; this level was chosen to ensure that even very light smokers could enroll), and be cognitively able to understand proposed research design (10-minute screening followed by random assignment to the experimental group or control group). This study was approved by Virginia Commonwealth University’s Institutional Review Board.

\section{Measures}

\section{Questionnaires}

At the first visit, participants completed questionnaires on demographics, substance abuse history, and dependence level (Fagerstrom Test of Nicotine Dependence or FTND [scores range from 0 to 10]; Heatherton, Kozlowski, Frecker \& Fagerstrom, 1991). At all visits, participants completed a series of paper and/or computerized questionnaires on tobacco use (in terms of cigarettes per day; CPD), use of nicotine replacement therapy (NRT), number of quit attempts in 
the last year (defined as at least 24 hours of abstinence), and stage of change (DiClemente et al., 1991).

Expired Air Carbon Monoxide

At Visits 1 and 2, breath samples were collected for measurement of expired air CO using a calibrated CO monitor (Vitalograph, Lenexa KS).

\section{Procedure}

Potential participants were recruited via flyers aimed at smokers, which were placed at the recovery center and at various sites in the community. The study consisted of two visits and a follow-up phone call, as described below.

\section{Visit 1}

All participants provided written consent, and then completed a series of paper and computerized questionnaires, as described above. Breath samples were collected for measurement of expired air $\mathrm{CO}$.

Urn randomization (via computer, based on gender and cigarettes per day) was used to assign study participants to one of two groups: the intervention group (C-BMI) or a control group that received resource information. An intervention authoring tool called the Computerized Intervention Authoring System, developed for previous work (e.g., Ondersma, Svikis \& Schuster, 2007; Ondersma et al., 2012), was used to develop the intervention in this study. The software uses a laptop or Tablet PC, and presents all information aurally and visually. One of a number of three-dimensional animated narrators provides explanations, reads questions (as well as answers, when clicked) and interprets feedback. This narrator also "reflects" back information provided by the participant, thus providing significant synchronous interaction. For the current study, the participants interacted with the computer via multiple- 
choice or checkbox responses (no typing or speaking was required). The intervention uses the 5As model including an assessment of current motivation to change, use of a Motivational Interviewing (MI) approach for those who are not ready to make a quit attempt, and provides assistance with a change plan for those who are ready to make a quit attempt. This software has been shown to be highly acceptable and easy to use (Ondersma, Chase, Svikis, \& Schuster, 2005), and a single 20-minute intervention using this approach led to reductions in drug use as compared to an assessment-only control group (Ondersma et al., 2007; Ondersma, Svikis, Thacker, Beaaty, \& Lockhart, 2014). This intervention has also been shown to increase smoking abstinence among pregnant women, compared to those not receiving the computerized intervention (Ondersma et al., 2012).

\section{Computerized Brief Motivational Intervention (C-BMI) Group. The C-BMI used a 5As} framework. Following questions about smoking (Ask), as well as a brief series of questions used to provide feedback later in the program, a video featuring a medical practitioner appeared on the screen. Using a script, the practitioner advised study participants to quit smoking using a nonconfrontational approach (Advise). Following the video, the software proceeded with an assessment of the participant's readiness to set a quit date (Assess). Depending upon the participant's response, this assessment was followed by two options:

A) A motivational "discussion" with the computer about his/her thoughts about smoking and quitting. This included a "pros and cons" exercise in which the participant expresses the factors for and against change from his/her point of view, as well as receives normative feedback regarding smoking and its associated risks. Throughout, the narrator reflected information provided by the participant (e.g., "On one hand, you really like how smoking helps you relax and you think it would be very hard to quit; on the other hand, 
you really are concerned about the effect of smoking on your health"). Finally, "change talk" (language associated with desire for change, ability to change, reasons to change, need to change, or commitment to change) was elicited using methods such as asking for elaboration regarding the "cons" of smoking or asking the participant to envision the advantages of being smoke-free; or

B) Assistance with a quit plan, including setting a quit date, identifying specific plans to assist success (such as telling others of the quit plan, throwing out tobacco products and paraphernalia, or using nicotine replacement), reinforcement of benefits of quitting, identification of triggers and obstacles, problem-solving around the latter, and identification of support options (Assist and Arrange).

The total C-BMI took approximately 30 minutes to complete. After the C-BMI was completed, participants were given an information sheet about resources to assist with smoking cessation, such as The Virginia Quitline. The Virginia Quitline is part of the North American Quitline Consortium (NAQC) and provides telephone counseling, internet-based programs and referrals to community programs.

Resource Information Condition (Control Group). Participants randomized to the control group were given an information sheet about quitting smoking resources, as described above.

\section{$\underline{\text { Nicotine Replacement Treatment }}$}

After the C-BMI or information, all participants interested in quitting smoking were offered NRT (patches and/or gum were offered in this study), free of charge for up to 10 weeks following randomization. A physician-approved NRT protocol was used to determine the appropriate use of NRT, appropriate doses, and length of treatment, based on the number of cigarettes smoked per day. 
Visit 2

All participants, regardless of study arm, were asked to visit the RCO for a follow-up visit four weeks after the intervention. Measures included those questionnaires used in the initial visit, as well as use of the NRT, and were administered using the same computer software. An expired air CO sample was also obtained. Additional NRT was provided as needed.

Visit 3 (follow-up phone call)

Finally, participants were contacted six weeks after Visit 2 and completed questionnaires about tobacco use and self-reported quit status, stage of change, and use of NRT. Participants received $\$ 40$ in gift cards for their participation in the study.

\section{Data preparation}

Data were entered into an SPSS (Version 21.0) database. Responses for the question “Are you seriously interested in quitting?" were collapsed to create a dichotomous variable (interested in quitting in the next 30 days/already quit vs. interested in quitting in the next six months/no interest in quitting). To assess quit status, self-reported seven-day point prevalence plus CO levels were examined. To confirm quit status, participants had to report both not smoking in the past seven days, as well as a CO level of 8ppm or less (SRNT, 2002).

\section{Data analysis}

Data were analyzed using SPSS 21.0 and SAS 9.3 (depending on the analysis).

Descriptive statistics were used to determine overall interest in quitting and other demographic characteristics. The primary outcomes of interest were CO-confirmed 7-day point-prevalence abstinence and interest in quitting at four and ten weeks post-randomization. Data analysis for quit status was conducted with both an intent-to-treat approach (ITT; participants lost to follow- 
up were assumed to be treatment failures and to be smoking) and a responder-only approach (only participants who completed visits were analyzed).

\section{Primary analysis}

Logistic regression analyses were used to assess the intervention differences seven-day point prevalence quitting (using an ITT approach), responder-only quitting, and interest in quitting at Visits 2 and 3. Baseline number of cigarettes per day and use of NRT (at Visit 1) were included as covariates.

\section{Secondary analysis}

Mixed model repeated measures ANOVAs with unstructured covariance for within subject variance were conducted to assess the intervention (C-BMI vs. control group) across two (Visit 1 and Visit 2; CO only) or three time points (Visit 1, Visit 2, and Visit 3) for CPD, and number of quit attempts. The model fit included two between subjects factors (Group and NRT) and one within subjects factor (Visit) as well as all possible two and three-way interaction terms between these main effects. For all ANOVAs, receipt of NRT at Visit 1 was used as a covariate (regardless of whether or not NRT was received at Visit 2). For ANOVAs with significant interactions, least squares means tests with a Tukey-Kramer adjustment were used to clarify differences between means (15 comparisons for CPD, 6 comparisons for number of quit attempts) Comparisons for which $p$ values less than 0.05 are reported as significant. 


\section{Participants}

\section{RESULTS}

Figure 1 shows the participant flow. One hundred and fifty-one participants were enrolled and 97 completed the study. All participants were current cigarette smokers in recovery from addiction to alcohol or other drugs (by self-report). Primary drugs of abuse included alcohol (39\%), cocaine (21\%) and heroin (17\%). Most participants reported receiving current outpatient treatment (74\%; this included attending alcoholics anonymous meetings or similar meetings) or inpatient treatment (6\%; inpatients at another facility were allowed to attend meetings at the organization where this study was conducted). Participants had been in recovery for an average of $2.7(\mathrm{SD}=4.90)$ years. Table 1 describes the demographic and smoking characteristics of participants, by group. As seen in Table 1, groups did not significantly differ by any demographic or smoking characteristic.

\section{Initial Interest in quitting}

At Visit 1, over a third of participants expressed an interest in quitting in the next 30 days (39\%) and another third expressed an interest in quitting in the next six months (36\%).

\section{Follow up participation rates}

In the C-BMI group, $78 \%$ of participants completed Visit 2 and $67 \%$ completed Visit 3. In the control group, $75 \%$ of participants completed Visit 2 and $62 \%$ completed Visit 3 . No demographic differences were observed between participants who completed or did not complete Visit 2. One difference was observed between participants who completed the entire study and those who did not: participants who completed all three visits reported smoking more CPD at Visit $1(\mathrm{t}(150)=4.48, \mathrm{p}=0.036$; mean $=18.53[\mathrm{SD}=9.06])$ compared to those who did not complete the entire study (mean CPD $=15.20[\mathrm{SD}=9.57]$ ). 


\section{Use of NRT}

Sixty-four percent of participants asked for NRT at Visit 1 and $66 \%$ asked for NRT at Visit 2. At Visit 2, of those who were given NRT, 94\% said they used the NRT provided. At Visit 3, 89\% said they used the NRT provided.

One significant demographic difference was observed between participants who chose to receive NRT compared to those who did not choose NRT. Participants who chose NRT were more likely to report that they wanted to quit in the next 30 days $\left(\chi^{2}=32.03 ; \mathrm{p}=.000 ; 56 \%\right)$ compared to those who chose NRT but reported that they wanted to quit in the next 6 months or did not want to quit (44\%).

\section{Intervention Effects}

\section{Primary Analysis}

As shown in Table 2, logistic regression analyses revealed no significant differences between the C-BMI group and control group for self-reported seven-day point prevalence abstinence at Visits 2 and 3, for both ITT analysis and responder-only analysis. For analyses including CO-confirmed abstinence, because no participants were abstinent in the control condition, logistic regression could not be conducted.

For ITT analysis, at Visit $2(\mathrm{n}=151) 7.4 \%$ of participants in the C-BMI group were abstinent (by self-report) compared to $2.9 \%$ in the control group. Similarly, at Visit $3(\mathrm{n}=97)$, $6.1 \%$ of the participants in the C-BMI group were abstinent (by self-report) compared to $2.9 \%$ in the control group $(\mathrm{p}=0.35)$ For responder-only analysis, at Visit $2(\mathrm{n}=116) 9.4 \%$ of participants in the C-BMI group were abstinent (by self-report) compared to $3.8 \%$ in the control group ( $\mathrm{p}=0.243)$. At Visit $3(\mathrm{n}=97), 11.1 \%$ of the participants in the C-BMI group were abstinent (by self-report) compared to $4.7 \%$ in the control group $(\mathrm{p}=0.251)$. 
Using ITT analysis, when CO levels were included to self-reported quitting to confirm quitting (available at Visit 2 only: 8 ppm or less), $5 \%$ of participants in the C-BMI group were abstinent at Visit 2, compared to $0 \%$ in the control group (n.s.). Using responder-only analysis, when $\mathrm{CO}$ levels were included to confirm quit status, $6.3 \%$ of participants in the C-BMI group were abstinent at Visit 2, compared to $0 \%$ in the control group (n.s.).

Logistic regression analyses revealed a significant difference between the C-BMI group and control group in response to the question "Are you seriously interested in quitting smoking in the next 30 days?" at Visit 2, as shown in Table 2. At Visit 2, 64\% of the participants in the C-BMI group said that they were either seriously thinking about quitting in the next 30 days, or had already quit, compared to the control group (37\%). No significant differences between groups were observed at Visit 3.

\section{Secondary Analysis}

As shown in Table 2, significant interactions of Visit by NRT were observed for CPD. For participants who received NRT at Visit 1, significant reductions in CPD were observed at Visits 2 and 3 (Visit 1 mean $=17.27$ [SD = 9.42]; Visit 2 mean $=8.78$ [SD = 7.05]; Visit 3 mean $=8.22[\mathrm{SD}=7.43])$. Similarly, for participants who did not receive NRT, significant reductions in CPD were observed at Visits 2 and 3 (Visit 1 mean $=17.53$ [SD = 9.31]; Visit 2 mean =14.56 [SD = 8.47]; Visit 3 mean $=14.32[\mathrm{SD}=8.18]$ ). However, at Visits 2 and 3 , participants who received NRT at Visit 1 reported smoking significantly fewer CPD, compared to participants who did not receive NRT at Visit 1.

A significant interaction between group and receipt of NRT at Visit 1 was observed for number of quit attempts; however, post hoc tests did not reveal any significant differences 
between means. Last, a main effect of Visit was observed for $\mathrm{CO}$; reductions across visits were observed $($ Visit 1 mean $=19.85$ [9.83]; Visit 2 mean $=17.63[10.44]$ 


\section{CONCLUSIONS}

Although tobacco use is high among individuals with SUDs, treatment is limited. Further, when treatment is offered (such as the 5As approach), the complete model is not often used (i.e., treatment providers ask and assess, and may advise, but do not often assist, or arrange; Association of American Medical Colleges, 2007; Jamal, Dube, Malarcher, Shaw \& Engstrom, 2012; Quinn et al., 2009), thus highlighting a gap between research and clinical practice. One approach to improving rates of intervention for tobacco use may be to use computer-delivered interventions.

This study showed that individuals in recovery from SUDs are very interested in quitting smoking, and that a computerized, brief motivational intervention delivered in a RCO is a feasible intervention to implement in this population. Findings regarding participants' desire to quit smoking are similar to previous work (e.g., Nahvi et al., 2006). Results also showed that participants were very interested in trying NRT. These findings underscore the importance of offering smoking cessation services to substance users in recovery.

The C-BMI had several effects. Overall, while quit rates were not significantly different between groups, the improvement in quit rates observed in the C-BMI (5 to 7\%, depending on analysis) are in line with the absolute rates observed for physician advice, minimal counseling, and low-intensity contact (Fiore et al., 2008), and could result in meaningful population-wide effects. Second, participants in the C-BMI, compared to the control group, reported a greater interest in quitting smoking at Visit 2 (4 weeks after the C-BMI), although this difference was not sustained throughout the study. These results suggest that a C-BMI may be a promising intervention for smokers who are also in recovery from substance abuse. 
While other studies have shown that smoking cessation interventions can be effective for individuals in treatment for substance abuse disorders (e.g., Khara \& Okoli, 2011) or effective at the end of treatment but not at follow-up (for review, see Prochaska et al., 2004), not all studies have reported significant differences between intervention and control groups. For example, in a recent study using a cognitive behavioral smoking cessation intervention among smokers receiving alcohol detoxification treatment, no significant differences between the intervention and control groups were observed for quit rates. In addition, low overall quit rates were observed (5.8\% after the intervention, 2.9\% at six-month follow-up; Mueller, Petitjean \& Wiesbeck, 2012). Other work has also shown small (although significant) differences between intervention and control groups. Specifically, a meta-analysis of smoking cessation trials for individuals being treated for substance abuse disorders found an overall post-treatment quit rate of $12 \%$ for intervention groups and $3 \%$ for control groups (Prochaska et al., 2004). Finally, while computerized interventions have been found to be effective for smoking cessation, the effects may be small (Chen et al., 2012). Overall, the quit rates observed in the current study are particularly noteworthy given that participants did not have to be interested in quitting in order to participate in the study.

Other results showing reduced CPD and reduced CO levels for both groups are very encouraging. In fact, among older adults, simply reducing the number of cigarettes smoked per day is associated with an increased likelihood of cessation (Falba, Jofre-Bonet, Busch, Duchovny \& Sindelar, 2004). Results showing better outcomes for participants who chose to receive NRT (for example, fewer CPD at follow-up visits) are consistent with other work showing that NRT can help smokers cut down on the number of cigarettes smoked per day (Stead \& Lancaster, 2007).

Several limitations should be highlighted. Given the provision of NRT to both groups, the smoking-related assessment, and the provision of smoking cessation information including the 


\section{Targeting Tobacco in a Community-Based Addiction Recovery Cohort}

Virginia Quitline, the intervention may not have been sufficiently different from the control group. In addition, simply talking to a research assistant about cigarette smoking may have been enough to create some behavior change in the control group. Also, all participants were recruited via response to a flyer, which may have suppressed brief intervention effects because these participants were already motivated to quit smoking. Brief interventions are best when used proactively, thus obtaining a healthy proportion of participants without any interest in quitting.

Another limitation is that the small sample size limited power as well as our ability to examine subgroup differences. Assuming a moderate effect size, 64 participants per treatment arm would have been ideal in order to observe an effect (Cohen, 1988). Unfortunately, while the number of participants who completed Visit 2 was 64 in the C-BMI group, only 52 completed Visit 2 in the control group, and fewer participants completed Visit 3. Also, the wording of our question about the number of quit attempts in the past year (asked at each visit) meant that overlap occurred between timepoints; this may have affected our findings for this measure. Finally, as this was a preliminary study in this population, the follow up period was short (10 weeks). Future studies with this population should include a longer follow-up period.

Results from this preliminary study support the data that show that recovering substance users are interested in quitting smoking, and indicate that a C-BMI is feasible in a recovery community organization (RCO). Even among a population in which not all individuals are highly motivated to quit, a C-BMI in this setting can lead to positive smoking-related behavior change. Providing smoking cessation services, such as a C-BMI, through RCOs is equally important as providing these services during more formal inpatient or outpatient treatment. In addition, smoking cessation services offered through RCOs have the potential to reach a broader range of individuals: many individuals attend RCOs while waiting for formal treatment, after 
formal treatment has ended, or in place of formal treatment. Finally, recent research has shown that treating tobacco addiction can actually improve long-term recovery (continued sobriety from alcohol/other drugs; Gulliver, Kamholz, \& Helstrom, 2006; Prochaska, Delucchi \& Hall, 2004). C-BMIs, along with other smoking cessation interventions, have the potential to significantly reduce the burden of smoking and related morbidity and mortality for individuals with SUDs.

\section{CONFLICT OF INTEREST}

Steven J. Ondersma is part owner of Interva, Inc., the company that licenses the authoring tool used to create the computer-delivered intervention. The other authors have no conflicts of interest to report.

\section{ACKNOWLEDGEMENTS}

The authors would like to thank the recovery community organization involved in this study, for providing access to clients and assisting with the project.

\section{FUNDING}

This work was funded by a Presidential Research Incentive Project (PRIP) Grant from Virginia Commonwealth University to ABB. Some recruitment and some statistical guidance was funded by a Clinical Translational Science Award (UL1TR000058) to Virginia Commonwealth University. The authors would also like to thank Leroy Thacker and Yunyun Wu from the Department of Biostatistics at VCU for statistical assistance. 


\section{REFERENCES}

Association of American Medical Colleges (2007). Physician behavior and practice patterns related to smoking cessation: a report prepared for the American Legacy Foundation. Washington, D.C.

Centers for Disease Control (2008). Smoking-Attributable Mortality, Years of Potential Life Lost, and Productivity Losses --- United States, 2000 - 2004. Morbidity and Mortality Weekly Report, 57(45), 889-894.

Centers for Disease Control (2012). Current cigarette smoking among adults-United States, 2011. Morbidity and Mortality Weekly Report, 61(44), 1226-1228.

Chen, Y. F., Madan, J., Welton, N., Yahaya, I., Aveyard, P., Bauld, L., ... \& Munafò, M. R. (2012). Effectiveness and cost-effectiveness of computer and other electronic aids for smoking cessation: a systematic review and network meta-analysis. Prepress Projects Limited.

Cohen, J. (1988). Statistical power analysis for the behavioral sciences. New Jersey: Lawrence Erlbaum Associates.

DiClemente, C.C., Prochaska, J.O., Fairhurst, S., Velicer, W.F., Rossi J.S., \& Velasquez, M. (1991). The process of smoking cessation: An analysis of precontemplation, contemplation and contemplation/action. Journal of Consulting and Clinical Psychology, 59, 295-304.

Falba, T., Jofre-Bonet, M., Busch, S., Duchovny, N., \& Sindelar, J. (2004). Reduction of quantity smoked predicts future cessation among older smokers. Addiction, 99(1), 93102. doi: 10.1111/j.1360-0443.2004.00574.x

Ferreira-Borges C (2005). Effectiveness of a brief counseling and behavioral intervention for smoking cessation in pregnant women. Preventive Medicine, 41(1), 295-302. doi: 10.1016/j.ypmed.2004.11.013

Fiore, M. (2008). Treating tobacco use and dependence: 2008 update: Clinical practice guideline. DIANE Publishing.

Friedman, P. D., Jiang, L., \& Richter (2008). Cigarette smoking cessation services in outpatient substance abuse treatment programs in the United States. Journal of Substance Abuse Treatment, 34, 165-172. doi: 10.1016/j.jsat.2007.02.006

Gulliver SB, Kamholz BW, Helstrom AW. (2006). Smoking cessation and alcohol abstinence: what do the data tell us? Alcohol Research and Health, 29(3):208-12.

Heatherton, T.F., Kozlowski, L.T., Frecker, R.C., \& Fagerström, K.O. (1991). The Fagerström test for nicotine dependence: a revision of the Fagerström tolerance questionnaire. British Journal of Addiction, 86, 1119-1127. doi: 10.1111/j.1360-0443.1991.tb01879.x

Heckman, C. J., Egleston, B. L., \& Hofmann, M. T. (2010). Efficacy of motivational interviewing for smoking cessation: a systematic review and meta-analysis. Tobacco Control, 19(5), 410-416. doi: 10.1136/tc.2009.033175

Hettema, J. E., \& Hendricks, P. S. (2010). Motivational interviewing for smoking cessation: a meta-analytic review. Journal of Consulting and Clinical Psychology, 78(6), 868-884. doi: $10.1037 / \mathrm{a} 0021498$

Hughes, J.R. (1995). Clinical implications of the association between smoking and alcoholism. In J.B. Fertig \& J.P. Allen (Eds).), Alcohol and tobacco: from basic science to clinical practice. NIAAA Research Monograph, vol. 30. (pp. 171-186). Bethesda MD: National Institutes on Health. 
Hunt, J. J., Cupertino, A. P., Garrett, S., Friedmann, P. D., \& Richter, K. P. (2012). How is tobacco treatment provided during drug treatment?. Journal of substance abuse treatment, 42(1), 4-15.

Jamal, A., Dube, S. R., Malarcher, A. M., Shaw, L., \& Engstrom, M. C. (2012). Tobacco Use Screening and Counseling During Physician Office Visits Among Adults-National Ambulatory Medical Care Survey and National Health Interview Survey, United States, 2005-2009. Use of Selected Clinical Preventive Services Among Adults-United States, 2007-2010, 61, 38.

Kalman D, Morissette SB, George TP (2005). Co-morbidity of smoking in patients with psychiatric and substance use disorders. American Journal of Addiction, 14(2), 106-23. doi: 10.1080/10550490590924728

Keppel, G. (1991). Design and analysis: A researcher's handbook. Englewood Cliffs, NJ: Prentice Hall.

Khara, M., \& Okoli, C. T. (2011). Smoking Cessation Outcomes among Individuals with Substance Use and/or Psychiatric Disorders. Journal of Addiction Research \& Therapy(2), 115. doi: /10.4172/2155-6105.1000115

Lai, D. T., Cahill, K., Qin, Y., \& Tang, J. L. (2010). Motivational interviewing for smoking cessation. Cochrane Database Systematic Reviews, 1. doi: 10.1002/14651858.CD006936

Mokdad AH, Marks JS, Stroup DF, Gerberding JL. (2004). Actual causes of death in the United States, 2000. Journal of the American Medical Association, 291(10), 1238-45. doi: 0.1001/jama.291.10.1238

Mueller, S. E., Petitjean, S. A., \& Wiesbeck, G. A. (2012). Cognitive behavioral smoking cessation during alcohol detoxification treatment: A randomized, controlled trial. Drug and Alcohol Dependence. doi: 10.1016/j.drugalcdep.2012.05.026

Nahvi S., Richter K., Li X., Modali L., Arnsten J. (2006). Cigarette smoking and interest in quitting in methadone maintenance patients. Addictive Behaviors, 31, 2127-34. doi: 10.1016/j.addbeh.2006.01.006

Ondersma, S. J., Chase, L., Svikis, D. S. \& Schuster, C. R. (2005). Computer-based brief intervention for perinatal drug use. Journal of Substance Abuse Treatment, 28, 305-312. doi: $10.1016 /$ j.jsat.2005.02.004

Ondersma, S. J., Svikis, D. S. \& Schuster, C. R. (2007). Computer-based brief motivational intervention for postpartum drug use: A phase II randomized clinical trial. American Journal of Preventive Medicine, 32(3), 231-238.

Ondersma, S. J., Svikis, D. S., Lam, P. K., Connors-Burge, V. S., Ledgerwood, D. M., \& Hopper, J. A. (2012). A randomized trial of computer-delivered brief intervention and lowintensity contingency management for smoking during pregnancy. Nicotine \& Tobacco Research, 14(3), 351-360. doi: 10.1093/ntr/ntr221

Ondersma, S. J., Svikis, D. S., Thacker, L. R., Beatty, J. R., \& Lockhart, N. (2014). Computerdelivered screening and brief intervention (e-SBI) for postpartum drug use: A randomized trial. Journal of substance abuse treatment, 46(1), 52-59.

Orleans CT, Hutchinson D. (1993). Tailoring nicotine addiction treatments for chemical dependency patients. Journal of Substance Abuse Treatment, 10(2),197-208. doi: 10.1016/0740-5472(93)90045-4

Pbert, L., Druker, S., DiFranza, J. R., Gorak, D., Reed, G., Magner, R., Sheetz, A.H., \& Osganian, S. (2011). Effectiveness of a School Nurse-Delivered Smoking-Cessation Intervention for Adolescents. Pediatrics, 128(5), 926-936. doi: 10.1542/peds.2011-0520 
Prochaska JJ, Delucchi K, Hall SM. (2004). A meta-analysis of smoking cessation interventions with individuals in substance abuse treatment or recovery. Consulting and Clinical Psychology, 72(6), 1144-56. doi: 10.1037/0022-006X.72.6.1144

Prochaska, J. J. (2010). Failure to treat tobacco use in mental health and addiction treatment settings: A form of harm reduction?. Drug and Alcohol Dependence, 110(3), 177-182. doi: 10.1016/j.drugalcdep.2010.03.002

Quinn, V.P., Hollis, J.F., Smith, K.S., Rigotti, N. A., Solberg, L. I., Hu, W., \& Stevens, V.J. (2009). Effectiveness of the 5-As tobacco cessation treatments in nine HMOs. Journal of General Internal Medicine, 24(2), 149-154. doi: 10.1007/s11606-008-0865-9

Reich MS, Dietrich MS, Finlayson AJ, Fischer EF, Martin PR. (2008). Coffee and cigarette consumption and perceived effects in recovering alcoholics participating in Alcoholics Anonymous in Nashville, Tennessee, USA. Alcoholism: Clinical and Experimental Research, 32(10), 1799-806.

Schroeder, SA, Morris, Chad D. (2010). Confronting a neglected epidemic: tobacco cessation for persons with mental illnesses and substance abuse problems. Annual Review of Public Health, 31, 237-314. doi: 10.1146/annurev.publhealth.012809.103701

Shahab, L., \& McEwen, A. (2009). Online support for smoking cessation: a systematic review of the literature. Addiction, 104(11), 1792-1804. doi: 10.1111/j.1360-0443.2009.02710.x

SRNT Subcommittee on Biochemical Verification. (2002). Biochemical verification of tobacco use and cessation. Nicotine \& Tobacco Research, 4, 149-159.

Stead LF, Bergson G, Lancaster T. (2008). Physician advice for smoking cessation. Cochrane Database Systematic Reviews, (2), CD000165. doi: 10.1002/14651858.CD000165.pub4

Stead, L. F., \& Lancaster, T. (2007). Interventions to reduce harm from continued tobacco use. Cochrane Database Systematic Reviews, 3(3). doi: 10.1002/14651858.CD005231 


\section{TABLES}

Table 1: Demographic Characteristics (means and standard deviations) of Participants (at Visit 1; $N=151$ )

\begin{tabular}{|l|c|c|c|c|}
\hline & $\begin{array}{l}\text { C-BMI } \\
\text { Experimental } \\
\text { Group; N } 82)\end{array}$ & $\begin{array}{l}\text { Information only } \\
\text { Control Group; } \\
\text { N=69) }\end{array}$ & Total & $\begin{array}{l}\chi^{2} \text { or F test and } \\
\text { p value }\end{array}$ \\
\hline Age & $41.58(11.19)$ & $42.29(11.31)$ & $41.91(11.21)$ & $0.15 ; 0.703$ \\
\hline $\begin{array}{l}\text { Length of time in } \\
\text { recovery (days) }\end{array}$ & $1179.84(2009.78)$ & $786.09(1472.11)$ & $\begin{array}{c}998.71 \\
(1787.88)\end{array}$ & $1.82 ; 0.180$ \\
\hline Cigarettes per day & $17.30(9.17)$ & $17.44(9.62)$ & $17.36(9.35)$ & $0.01 ; 0.929$ \\
\hline $\begin{array}{l}\text { Number of } \\
\text { previous quit } \\
\text { attempts (past } \\
\text { year) }\end{array}$ & $2.64(6.43)$ & $1.90(4.61)$ & $2.30(5.67)$ & $0.64 ; 0.425$ \\
\hline FTND score & $5.91(2.03)$ & $5.64(1.97)$ & $5.79(2.00)$ & $0.72 ; 0.399$ \\
\hline $\begin{array}{l}\text { Expired air CO } \\
\text { level (ppm) }\end{array}$ & $19.74(10.33)$ & $19.97(9.28)$ & $19.85(9.83)$ & $0.02 ; 0.888$ \\
\hline$\%$ Caucasian & 48 & 44 & 46 & $0.27 ; 0.965$ \\
\hline $\begin{array}{l}\text { \% Interested in } \\
\text { quitting in the } \\
\text { next 30 days }\end{array}$ & 44 & 33 & 39 & $0.93 ; 0.379$ \\
\hline$\%$ male & & & & \\
\hline $\begin{array}{l}\% \text { who opted to } \\
\text { receive NRT at } \\
\text { Visit 1 }\end{array}$ & 45 & 61 & 64 & $0.04 ; 0.840$ \\
\hline
\end{tabular}


Table 2: Logistic Regression Results for Effects of C-BMI

\begin{tabular}{|c|c|c|c|c|}
\hline & $\begin{array}{l}\% \text { in C-BMI } \\
\text { group; control } \\
\text { group }\end{array}$ & OR & $95 \% \mathrm{CI}$ & Sig. \\
\hline \multicolumn{5}{|l|}{ Visit 2} \\
\hline $\begin{array}{l}\text { Self-reported 7- } \\
\text { day point } \\
\text { prevalence } \\
\text { abstinence } \\
\text { (ITT) }\end{array}$ & $7.4 ; 2.9$ & 0.39 & $(0.77,2.03)$ & 0.265 \\
\hline $\begin{array}{l}\text { Self-reported 7- } \\
\text { day point } \\
\text { prevalence } \\
\text { abstinence } \\
\text { (responder- } \\
\text { only) }\end{array}$ & $9.4 ; 3.8$ & 0.41 & $(0.08,2.20)$ & 0.297 \\
\hline $\begin{array}{l}\text { CO-confirmed } \\
\text { abstinence } \\
\text { (responder- } \\
\text { only) }\end{array}$ & $6.3 ; 0$ & N/A & N/A & N/A \\
\hline $\begin{array}{l}\text { CO-confirmed } \\
\text { abstinence } \\
\text { (ITT) }\end{array}$ & $5 ; 0$ & N/A & N/A & N/A \\
\hline $\begin{array}{l}\text { Interest in } \\
\text { quitting in the } \\
\text { next } 30 \text { days }\end{array}$ & $64 ; 37$ & 2.82 & $(1.24,6.39)$ & 0.013 \\
\hline \multicolumn{5}{|l|}{ Visit 3} \\
\hline $\begin{array}{l}\text { Self-reported 7- } \\
\text { day point } \\
\text { prevalence } \\
\text { abstinence } \\
\text { (ITT) }\end{array}$ & $6.1 ; 2.9$ & 0.44 & $(0.08,2.47)$ & 0.350 \\
\hline $\begin{array}{l}\text { Self-reported 7- } \\
\text { day point } \\
\text { prevalence } \\
\text { abstinence } \\
\text { (responder- } \\
\text { only) }\end{array}$ & $11.1 ; 4.7$ & 0.43 & $(0.08,2.39)$ & 0.334 \\
\hline $\begin{array}{l}\text { Interest in } \\
\text { quitting in the } \\
\text { next } 30 \text { days }\end{array}$ & $43 ; 33$ & 1.36 & $(0.56,3.32)$ & 0.502 \\
\hline
\end{tabular}


Targeting Tobacco in a Community-Based Addiction Recovery Cohort 
Table 3: C-BMI Effects: Results of Linear Mixed Models Repeated Measures ANOVAs

\begin{tabular}{|c|c|c|c|c|c|c|c|c|c|c|c|c|c|c|}
\hline & \multicolumn{2}{|l|}{ Group } & \multicolumn{2}{|l|}{ Visit } & \multicolumn{2}{|c|}{$\begin{array}{l}\text { Group by } \\
\text { Visit }\end{array}$} & \multicolumn{2}{|l|}{ NRT } & \multicolumn{2}{|c|}{$\begin{array}{l}\text { Group by } \\
\text { NRT }\end{array}$} & \multicolumn{2}{|c|}{ Visit by NRT } & \multicolumn{2}{|c|}{$\begin{array}{l}\text { Group by Visit } \\
\text { by NRT }\end{array}$} \\
\hline & $\mathrm{F}$ & $\mathrm{p}$ & $\mathrm{F}$ & $\mathrm{p}$ & $\mathrm{F}$ & $\mathrm{p}$ & $\mathrm{F}$ & $\mathrm{p}$ & $\mathrm{F}$ & $\mathrm{p}$ & $\mathrm{F}$ & $\mathrm{p}$ & $\mathrm{F}$ & $\mathrm{p}$ \\
\hline CPD & $0.20^{1}$ & 0.653 & $48.09^{2}$ & 0.000 & $0.52^{2}$ & 0.653 & $9.53^{3}$ & 0.002 & $0.53^{3}$ & 0.468 & $6.67^{4}$ & 0.002 & $1.19^{4}$ & 0.308 \\
\hline $\mathrm{CO}$ & $0.12^{5}$ & 0.731 & $12.0^{6}$ & 0.001 & $0.10^{6}$ & 0.756 & $2.06^{6}$ & 0.153 & $0.09^{7}$ & 0.760 & $2.70^{6}$ & 0.103 & $0.55^{6}$ & 0.461 \\
\hline $\begin{array}{l}\text { Number of } \\
\text { quit attempts }\end{array}$ & $0.29^{8}$ & 0.593 & $0.42^{9}$ & 0.658 & $2.25^{9}$ & 0.110 & $0.00^{10}$ & 0.988 & $4.29^{10}$ & 0.040 & $0.19^{11}$ & 0.829 & $1.16^{11}$ & 0.317 \\
\hline
\end{tabular}

$1 \mathrm{df}(1,138$

${ }^{2} \mathrm{df}(2,112)$

${ }^{3} \mathrm{df}(1,134)$

${ }^{4} \mathrm{df}(2,110)$

$5 \mathrm{df}(1,149$

${ }^{6} \mathrm{df}(1,119)$

${ }^{7} \mathrm{df}(1,145)$

${ }^{8} \mathrm{df}(1,128)$

${ }^{9} \mathrm{df}(2,105)$

${ }^{10} \mathrm{df}(1,126)$

${ }^{11} \mathrm{df}(2,104)$ 
Targeting Tobacco in a Community-Based Addiction Recovery Cohort

\section{FIGURE CAPTION}

Figure 1. Participant flow diagram. 
Figure 1

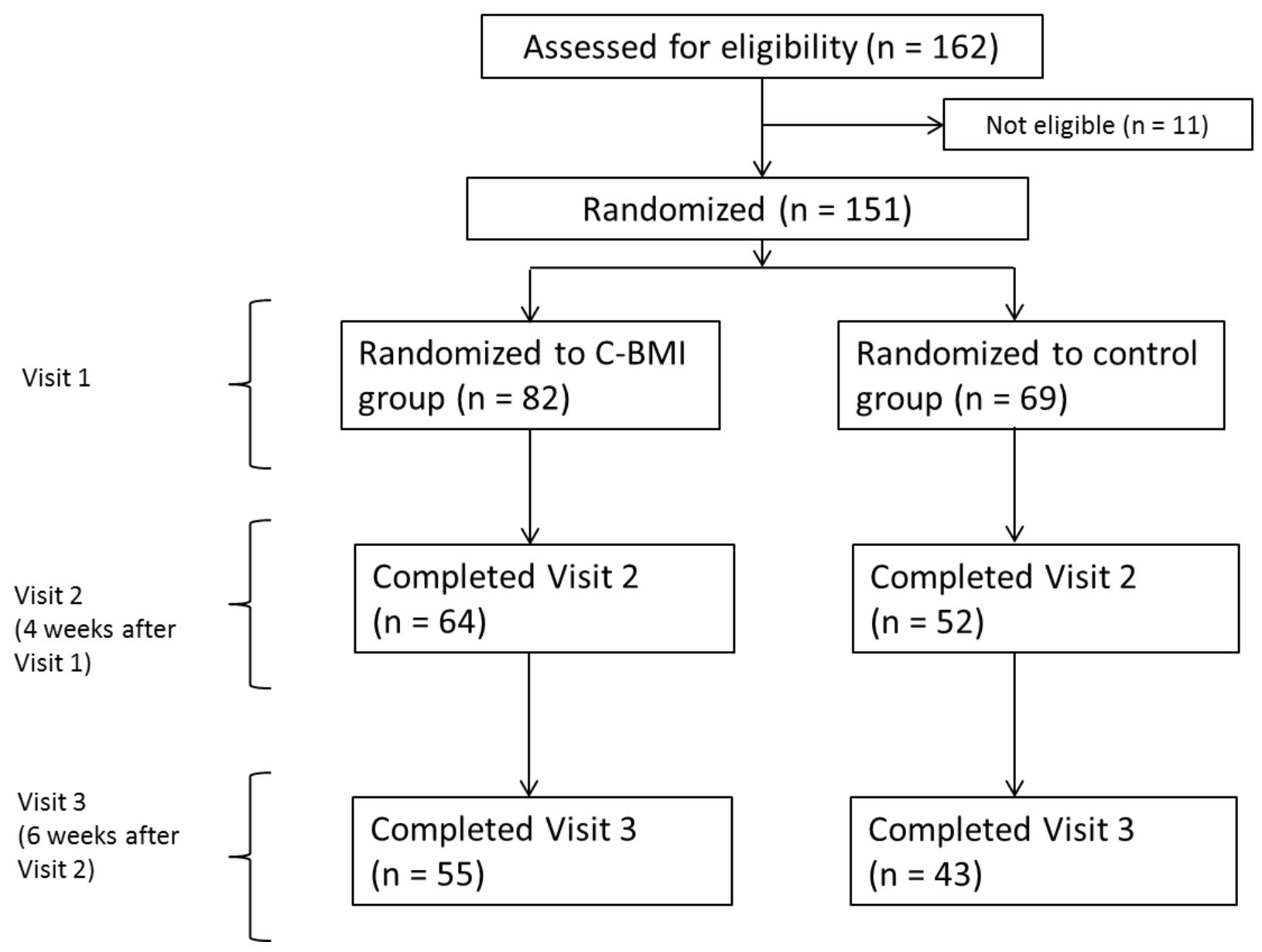

